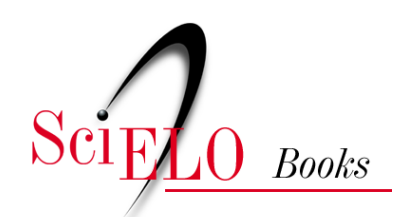

\title{
História Ambiental e as migrações no Reino Vegetal a domesticação e a introdução de plantas
}

\author{
Samira Peruchi Moretto
}

\section{SciELO Books / SciELO Livros / SciELO Libros}

MORETTO, S.P. História Ambiental e as migrações no Reino Vegetal: a domesticação e a introdução de plantas. In: GERHARDT, M., NODARI, E.S., and MORETTO, S.P., eds. História ambiental e migrações: diálogos [online]. São Leopoldo: Oikos; editora UFFS, 2017, pp. 109-122. ISBN: 978-8564905-68-9. https://doi.org/10.7476/9788564905689.0008.

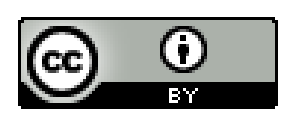

All the contents of this work, except where otherwise noted, is licensed under a Creative Commons Attribution 4.0 International license.

Todo o conteúdo deste trabalho, exceto quando houver ressalva, é publicado sob a licença Creative Commons Atribição 4.0.

Todo el contenido de esta obra, excepto donde se indique lo contrario, está bajo licencia de la licencia $\underline{\text { Creative Commons }}$ Reconocimento 4.0. 


\section{História Ambiental e as migrações no Reino Vegetal: a domesticação e a introdução de plantas}

Samira Peruchi Moretto

\section{Introdução}

Estudar a domesticação de uma espécie vegetal é um processo dinâmico, ultrapassa fronteiras e aponta a importância dos seres humanos para as frequentes modificações da paisagem. Caso se parta do pressuposto de que o meio ambiente está em constante transformação e que os seres humanos fazem parte deste contexto, pode-se observar que vivemos em associação com o meio circundante, mudando e adequando-nos a ele. A domesticação de plantas é exemplo bastante vivaz dessa correlação. Através da metodologia da História Ambiental, pode-se utilizar a domesticação de plantas para a compreensão de tais processos dinâmicos, envolvendo os seres humanos e a natureza. A História Ambiental, segundo Donald Worster, apresenta-se em uma nova premissa:

A história ambiental é, em resumo, parte de um esforço revisionista para tornar a disciplina da história muito mais inclusiva nas suas narrativas do que ela tem tradicionalmente sido. Acima de tudo, a história ambiental rejeita a premissa convencional de que a experiência humana se desenvolveu sem restrições naturais, de que os humanos são uma espécie distinta e "super-natural", de que as consequências ecológicas dos seus feitos passados podem ser ignoradas (2003, p. 199).

O cultivo de vegetais propiciou não somente a multiplicação, mas também certa independência dos seres humanos. A domesticação de plantas possibilitou e possibilita produção de matérias-primas e, mais importante ainda, a garantia de alimentos. Esforços para explicar a necessidade dos seres humanos em iniciarem a domesticação e as origens da agricultura apoiam-se em basicamente três fatores: mudança ambiental, pressão demográfica e mudanças na organização social. 
Por um longo período de tempo - cerca de sete milhões de anos todos os seres humanos que habitavam a Terra se alimentavam exclusivamente da coleta de plantas e da caça de animais (DIAMOND, 2008, p. 182). Não havia a produção de alimentos, pois os seres humanos dependiam dos proventos que a natureza fornecia. Diferentes fatores influenciaram para alterar seus hábitos alimentares e modos de obtenção de alimentos.

O crescimento demográfico também pode ser apontado como causa da falta de alimentos e, consequentemente, das expansões territoriais dos povos nos períodos Neolítico e Paleolítico (CAVALLI-SFORZA, 2003, p. 127). Todavia, o clima, o relevo e a vegetação influenciaram de forma direta e indireta na produção de alimentos pelos seres humanos. Houve a necessidade de plantio de alimentos para suprir a necessidade da população que enfrentou um crescimento demográfico significativo há cerca de 10 milhões de anos. A teoria da transcedentalidade aponta que podem ter ocorrido diferentes fatores responsáveis pelo início da domesticação de espécies vegetais e animais (CAVALLI-SFORZA, 2003, p. 133).

Autores como Brian Hayden, Neil Canuel e Jennifer Shanse que discutem a gênese da domesticação dos cereais, argumentam que o aumento da demanda por cereais, inicialmente para propósitos de fermentação para produção da cerveja, levou à domesticação de cereais para a fabricação da bebida. Expondo o trabalho de uma perspectiva comparativa global, os autores afirmam que parecem não existir exemplos etnográficos de simples caçadores-coletores primitivos que faziam álcool. Isto pode ser devido a um bom número de razões, como a falta de recipientes com tamanho ideal, ou de tecnologia de ebulição, a alta mobilidade dos grupos, ou outros fatores logísticos. Parece que apenas com o advento de caçadores-coletores complexos, semi-sedentários ou sedentários, como os do sudeste da Austrália, os primeiros relatos de bebidas alcoólicas começam a aparecer. Desta forma, houve também a necessidade de domesticar os componentes responsáveis pela fermentação. Os autores concluem que festejar e fabricar a cerveja, muito provavelmente, forneceu um elo fundamental entre o aumento da complexidade nas técnicas e a adoção de cultivo de cereais (HAYDEN et al., 2013, p. 102).

Oliver Dietrich realizou uma pesquisa a respeito dos grupos humanos que viveram em Göbekli Tepe, na Turquia, no período neolítico; e também aponta que fatores ligados à religiosidade foram responsáveis pela motivação destes grupos no que diz respeito à sedentarização. A antiga 
cidade de Göbekli Tepe era um local central de religiosidade para grupos caçadores/coletores, onde realizavam diferenciado sistema de crença transcendental. A religião e a construção de templos por estes grupos podem ser considerados os seus reais motivos para a sedentarização. $\mathrm{O}$ aparecimento precoce da arquitetura religiosa monumental em Göbekli Tepe está mudando profundamente a imagem de um dos momentos-chave da história, o surgimento da agricultura e da cannabis pecuária (DIETRICH, 2012, p. 51).

As inovações em práticas e de utensílios proporcionaram as expansões territoriais. A descoberta de novas fontes de alimentos, aliada ao desenvolvimento de novos meios de transporte e desenvolvimento do poderio militar, permitiram as primeiras grandes migrações humanas em massa. Porém, mesmo com tais avanços, os novos alimentos encontrados não foram suficientes para limitar os povos primitivos, que continuaram a praticar a caça e a coleta. Mesmo na atualidade, ainda existem povos coletores e caçadores, que não sobrevivem a partir das práticas agrícolas.

A maioria dos povos que habitaram o planeta sedentarizaram-se, mas o nível de sedentarização não foi o mesmo para todos os grupos sociais:

Povos diferentes iniciaram a produção de alimentos em diferentes períodos da pré-história. Alguns, como os aborígines australianos, nunca chegaram a este estágio. Entre aqueles que adquiriram o hábito, alguns, por exemplo, os antigos chineses, desenvolveram essa prática por conta própria, enquanto outros, inclusive os antigos egípcios, aprenderam com seus vizinhos (DIAMOND, 2008, p. 84).

Warren Dean afirmou que os indígenas brasileiros tiveram um processo mais lento de sedentarização, motivados pela abundância dos recursos naturais. Não havia a necessidade da preocupação com o estoque ou reservas de subsídios, já que havia uma densidade significativa de floresta a garantir sustento (1996, p. 43).

As práticas nômades diminuíram, já que havia a necessidade de tomar conta do que fora cultivado em locais estagnados. Ser caçador-coletor significava ter como função a busca incessante por comida, já que a falta levava à abstinência. Sedentarizar-se foi uma forma alternativa e cômoda para melhorar a produção de alimento. Portanto, a maior parte do desenvolvimento agrícola foi dependente das transferências de plantas (BEINART; MIDLETON, 2009, p. 161).

A sedentarização auxiliou a elevação da taxa demográfica. Consequentemente, pode-se afirmar que a prática da agricultura alterou o modo de vida das diferentes sociedades. Houve uma nova divisão nas tarefas dos 
grupos, já que uma parte da população ficaria responsável pelo cultivo da horta e dos pomares. As sociedades criaram suas relações sociais, políticas e militares, baseadas no novo sistema de produção de alimentos: a agricultura. O aumento populacional estimulou o incremento das técnicas para a produção alimentícia.

As primeiras formas de praticar a agricultura não eram tão agressivas e prejudiciais ao meio ambiente, comparadas às monoculturas em grande escala, praticadas após as colonizações do século XV. Os grupos sociais que se sedentarizaram tinham uma vida menos desgastante, comparados aos coletores-caçadores. Estes poderiam passar vastos períodos sem alimentos cultivados e precisavam de habilidades para garantir a caça. Contudo, os grupos que domesticavam plantas e animais também precisavam ser detentores de conhecimentos.

Os praticantes da agricultura deveriam estar atentos às condições do tempo e à fertilidade do solo. A caça e a coleta não foram abandonadas abruptamente; é um equívoco achar que houve rompimento de uma atividade em detrimento a outra, pois a caça, até a modernidade recente, complementou a alimentação de diferentes grupos. A agricultura foi acompanhada pela domesticação de animais. Os caçadores coletores da América, mesmo após a sedentarização, domesticavam cerca de três ou quatro espécies animais. Os cães foram os primeiros animais domesticados neste continente por estes grupos, pois auxiliavam na caçada (CROSBY, 1993, p. 39).

No entanto, praticar a agricultura modificou a paisagem e a relação do homem com a floresta. Warren Dean afirma que hábitos foram modificados, como a queimada na Mata Atlântica, que antes era utilizada para atrair a caça ou por mero descuido e que, deu vez a queimadas em grandes extensões para o uso da terra. A floresta que nunca havia sido queimada era fértil e livre de sementes invasoras, não necessitando de tantos cuidados. Assim, a floresta sofreu consequências diretas da agricultura. As queimadas e as derrubadas frequentes colocavam em risco a reestruturação natural do meio:

Todos os regimes agrícolas representam transtorno a um ecossistema natural. Na verdade, procuram congelar a secessão natural em seu estágio mais primitivo, introduzindo plantas cultivadas, que, em seu estado selvagem, tinham sido espécies precursoras. Esse tipo de lavoura chamado de itinerante ou de derrubada e queimada, é menos evasivo, porque imita a escala natural de perturbação e, em vez de congelar permanentemente o processo de sucessão, apenas exporá de forma temporária (DEAN, 1996, p. 43). 
Com a evolução das práticas agrícolas e do colonialismo, ocorreu um aumento e uma troca de espécies pelo mundo. Estas espécies eram provedoras de alimentos, serviam como condimentos, tinham funções medicinais ou eram oleaginosas, eram também fornecedoras de fibras. A fecundação de plantas, que antes era feita pela água, pelo vento e pelos animais ocasionalmente passou a ter interferência dos seres humanos, facilitando a dispersão e a germinação das sementes das plantas. Em alguns lugares, a domesticação de animais só foi possível com a introdução de espécies exóticas, gramíneas e forragens, que serviriam de alimento para os animais criados. A domesticação de plantas auxiliou no processo do crescimento demográfico dos seres humanos e alterou profundamente a sua relação com o meio natural. Charles Darwin, em alguns de seus estudos sobre evolução, coloca a domesticação como um claro exemplo da seleção em ação. Os seres humanos, intencionalmente ou inusitadamente, fizeram a seleção de certos traços. Junto com a comunicação e o uso de ferramentas, a domesticação de plantas e animais associados ao surgimento da agricultura foram um dos instrumentos fundamentais da evolução humana. Segundo Alfred Crosby, os detentores de tecnologia e conhecimento para domesticar obtiveram melhores resultados referentes à expansão:

Os povos que herdaram as plantas cultivadas e os animais domesticados das culturas avançadas do Sudeste da Ásia (europeus, indianos, chineses e outros) prosperaram e multiplicaram-se, mas se assim o fizeram foi tanto apesar quanto por causa de organismos, instituições e modos de civilização (1993, p. 40).

Questionamentos tais como "quando, como e por que?" despertaram o interesse de pesquisadores para estudar a domesticação de plantas e animais. O estudo e a história da domesticação geraram uma série de teorias e termos que se confundem e tendem a ser utilizados erroneamente. Segundo o pesquisador e geneticista Gideon Ladizinsky, atualmente professor da Hebrew University, em Israel, a definição do conceito dos termos agricultura, cultivo e domesticação são de suma relevância para o entendimento dos mesmos:

Agricultura, no sentido mais amplo pode ser considerada como uma estratégia de subsistência por intermédio da criação de plantas e animais, silvestres ou domesticados.

Cultivo define as atividades físicas que são relevantes e associadas com a agricultura. 
Domesticação - é um processo que é baseado no deslocamento genético das populações domesticadas, tornando-as mais bem adaptadas para o ambiente criado por cultivo, mas ao mesmo tempo, mal adaptado ao seu habitat original. Isso é geralmente aplicável às culturas de sementes que sob cultivo perderam o mecanismo de dispersão natural, em muitas plantas se deslocam a novos ambientes ou aplicação de propagação vegetativa que os tornam dependentes dos seres humanos, também é considerado como a domesticação (1998, p. 11).

A utilização de termos propostos por Ladizinsky pode facilitar no entendimento da história da domesticação, uma vez que esta aparece explicitamente como uma ação antrópica, passível de agentes humanos. Domesticação de plantas é realizada por humanos e motivada por escolhas. Algumas espécies domesticadas são preteríveis a outras. Existem muitos fatores que contribuem na escolha de uma espécie para domesticação, sendo estes econômicos, culturais, sociais, naturais, bem como adaptabilidade entre outros. Não há de se entender como um processo ingênuo, sem intrínsecas razões.

No Brasil, o processo de domesticação foi iniciado pelos indígenas que foram responsáveis pela difusão de muitas espécies. Os indígenas foram responsáveis pelas modificações complexas passíveis de estudos para melhor entendimento da diversidade local. A coexistência de grupos indígenas em certas áreas só foi possível após a domesticação de espécies alimentícias. Primordialmente, estas domesticações eram realizadas com espécies nativas, mesmo assim foram responsáveis pela alteração na flora.

O processo, denominado mais radical, decorrente da domesticação e principalmente da aclimatação de plantas, ocorreu após o processo de colonização da América. Foram muitas espécies introduzidas e aclimatadas neste período, modificando mais uma vez os biomas aqui existentes. Com a introdução de espécies exóticas pelos europeus, propiciou-se no Brasil a adaptação de milhares de espécies não nativas.

Muitas das plantas que foram aclimatadas no Brasil, ou levadas para outros países, não foram devidamente registradas. Tais notificações só começaram a ser regularizadas após a criação do Jardim Botânico, no Rio de Janeiro, após a chegada da família real portuguesa, no Brasil, em 1808. Mesmo sendo incumbência do Jardim Botânico, era priorizado o registro de saída e de entrada das plantas com interesses econômicos latentes (DEAN, 1996, p. 141). 


\section{A domesticação e a introdução de plantas como objeto de pesquisa}

Muitos trabalhos já foram feitos observando a domesticação e a migração de espécies vegetais. Como exemplo, pode ser utilizado o livro do Warren Dean, A Luta pela borracha no Brasil (1989), obra pioneira no estudo de tal temática. Michael Pollan, professor de jornalismo da Universidade de Berkley, que estuda há 25 anos a introdução e a utilização de plantas, realizou estudos a respeito da domesticação, considerou que as espécies de plantas e os animais, sem mencionar o mimetismo passaram por processos evolutivos de transformação, em que apreenderam formas de se destacar frente a outras espécies. Pollan afirma que existe a participação de outras espécies, além da antropização, no processo de migração de espécies:

Nós pensamos automaticamente em domesticação como algo que fazemos para outras espécies, mas faz sentido pensar também, como certas plantas e animais têm realizado para nós uma estratégia inteligente e evolutiva para avançar seus próprios interesses. As espécies que têm passado os últimos dez mil anos ou mais para descobrir a melhor forma de alimentar, curar, vestir, intoxicar (2001, p. XVI).

Propõe, desta forma, que a escolha por certas espécies a serem domesticadas, tendem a ocorrer não de forma natural, mas de acordo com as propriedades oferecidas pelas outras espécies aos seres humanos. Afirma, assim, que algumas espécies tiveram mais sucesso quanto à dispersão perante outras, denominando este fenômeno como "algumas lojas de sucesso da natureza". Assim como os seres humanos, as plantas também apresentam estratégias de sobrevivência.

As plantas apresentam características que promovem algumas transformações naturais que beneficiam os seres humanos de forma geral. As plantas são consideradas por Pollan como alquimistas da natureza, especialistas em transformar a água, o solo e a luz solar em uma matriz de substâncias preciosas. Assim como os seres humanos passaram por processos de transformação para se adaptarem ao meio ambiente, as plantas alteraramse a esta forma, mantiveram-se ou tornaram-se úteis aos seres humanos e a outros organismos do ecossistema a que elas pertencem. As plantas apresentam-se tão dinâmicas que os seres humanos não tendem a apreciar plenamente a sua complexidade e sofisticação.

Outros pesquisadores consideram que os seres humanos se destacam na relação de domesticação de espécies, como afirma Melinda A. Zeder, 
diretora de Arqueobiologia do Program of the Smithsonian Institution's National do Museu de História Natural da Universidade da Califórnia. A autora afirma que os seres humanos rapidamente assumiram um papel dominante, por serem livres para escolher entre as variantes genéticas de outras espécies, desta forma podendo manipular o comportamento e a domesticação de espécies (mesmo para seu próprio prejuízo). Afirma também que a domesticação não pode ser simplesmente definida como um acontecimento biológico ou um fenômeno cultural, mas, sim, precisa ser vista como um mutualismo biológico, em que a transformação biológica é catalisada pelo comportamento humano, através da aprendizagem e de influências culturais.

Zeder (2006) é editora do livro Documenting Domestication: New Genetic and Archaeological Paradigms, que faz uma análise sobre a interação dos seres humanos e as alterações no meio natural. O livro foi dividido basicamente em duas partes: animais e plantas. Já na introdução da obra os autores destacam que a relação dos seres humanos com o meio ambiente é bastante complexa e que nem sempre a causa ou o grau de interação podem ser mensuráveis e compreensíveis. No entanto, a pressão e a seleção humana geraram alterações nas demais espécies. Estas de fato influenciam umas às outras, mas nada é tão profundo como a ação humana. O próprio conhecimento dos seres humanos não somente foi capaz de catalisar mudanças, mas também soube analisar a dinâmica dos demais seres.

Warren Dean, ao pesquisar a domesticação e a disseminação da borracha, aponta quais foram os principais propósitos que levaram outros países a domesticarem esta espécie. A matéria-prima fornecida pela planta, a borracha, tornou-se um importante aparato nas crescentes indústrias mundiais. Após a descoberta de suas propriedades elásticas, passou a acompanhar o ferro e o aço dentro das indústrias. Neste caso, a principal motivação, ou "desejo", assim denominado por Pollan, foi o econômico. Produzir borracha em outros países significaria reduzir os elevados custos da importação.

Além dos problemas dos custos da importação, havia preocupação com quantidade de matéria-prima, uma vez que a quantidade de árvores nativas e produtoras de borracha foram declaradas, na metade do século XIX, como incipientes. Desta maneira, disseminar a planta significaria também suprir as necessidades mercadológicas. Porém, este processo de disseminação da planta não ocorreu de forma lícita.

Dean expôs como a borracha foi disseminada e amplamente motivada pela questão econômica, descartando a preocupação com o meio ambiente. 
Esta ambição descomedida fez com que o plantio ocorresse de forma diferenciada da ocorrência natural da espécie, isto é, para otimizar o espaço, foram plantadas árvores bem próximas umas das outras. Quando o fungo apareceu, sua dispersão foi facilitada pela proximidade das plantas, uma vez que ela ocorre de forma anemocoria (pelo vento). A proximidade das plantas fez também com que se dificultasse o tratamento das árvores afetadas pelo fungo. Segundo Dean, uma vez mais a ambição humana foi sobreposta às necessidades de um ecossistema.

\section{As migrações de espécies vegetais e interesses por trás das dispersões}

Estudar a domesticação e a disseminação de uma espécie significa entender redes sociais de interesse, além de questões ligadas às transformações ambientais. Stuart McCook, historiador, professor da Universidade de Guelph, optou por fazer uma história transnacional do café, seguindo as epidemias que o afetam. O café, bebida consumida em abundância nas mais diversas culturas, foi introduzido em vários países, incluindo o Brasil.

McCook legitima a contribuição do seu estudo das pragas para a história ambiental, afirmando que as epidemias agrícolas podem ser acidentais, mas elas não são aleatórias: são naturais e antrópicas. Os patógenos causadores de epidemias frequentemente seguem o movimento de pessoas; a expansão global das epidemias muitas vezes espelha a expansão global de pessoas:

Tal como as epidemias humanas, as epidemias agrícolas constituem-se em dispositivos úteis que permitem aos historiadores a condução de comparações seriais cruzadas no interior de uma sociedade, assim como comparações históricas de longa duração através de sociedades. As mudanças nos padrões e distribuição de uma epidemia necessariamente se refletem - e causam - mudanças nas relações entre as sociedades humanas e seus ambientes naturais. A história das epidemias agrícolas, portanto, pode oferecer aos historiadores uma importante ferramenta para a escrita da história ambiental das commodities e da agricultura (MCCOOK, 2009, p. 88).

Assim como o próprio processo de domesticação e disseminação, as epidemias agrícolas aparecem nas paisagens agrícolas movidas parcialmente por valores humanos. Portanto, são eventos fundamentalmente históricos, "situados em locais e tempos particulares, modelados simultaneamente por forças naturais e humanas" (MCCOOK, 2009, p. 3). 
Outras espécies domesticadas foram temas de outros pesquisadores. A batata, também estudada por Pollan, por sua tamanha importância, recebeu atenção de outros estudiosos. O inglês John Reader, autor da obra Potato: a story of the propitious esculent, analisa o processo de domesticação da batata, focando sua transferência da América do Sul para a Europa a partir de 1600. Na obra, o autor segue as etapas, os destinos e as consequências ecológicas e sociais da domesticação da batata por diferentes locais, fora do seu centro de origem (READER, 2008).

A batata foi considerada por Reader como planta de domesticação antiga, comparável com ao arroz, ao trigo e ao milho. Esses grãos espalharam-se pelo mundo todo e se consolidaram nas dietas de numerosos povos. São hoje os três primeiros alimentos cultivados e consumidos pela humanidade. O sucesso pela escolha da domesticação da batata deu-se principalmente pelo fato dela ser um cultivo confiável e produtivo e um alimento de fácil preparo e alta qualidade nutricional. Este tubérculo pode ser cultivado em terras e condições climáticas distintas das exigidas pelos grãos tradicionais e/ou em combinação com outros cultivos.

John Soluri, em sua obra Banana Cultures: Agriculture, Consumption, and Environmental Change in Honduras and the United State (2005), examinou a relação entre o consumo em massa de um produto tropical - banana, nos Estados Unidos, e as alterações ambientais e sociais em Honduras, durante o final do século XIX e o século XX, em função desta cultura. Soluri elenca questões sobre a temática da banana: patógenos persistentes, alteração da paisagem e, principalmente, como um produto por excelência consumido para subsistência passou a ser aceito internacionalmente, não deixando de fora uma análise bastante detalhada do mercado consumidor do produto.

Marcos Gerhardt (2013), que propôs fazer a história da erva-mate (Ilex paraguariensis), mostra como as sociedades da América Meridional se envolveram com seu extrativismo, cultivo, comércio e consumo, durante o século XIX e nas três primeiras décadas do XX. Utilizando a abordagem da história ambiental, o autor estudou a conservação dos ervais nativos e as mudanças socioambientais que estes sofreram durante o período abordado. Analisou também as ligações da atividade ervateira com os projetos de colonização e as iniciativas de expansão do mercado do mate por meio da propaganda baseada no conhecimento científico da época.

No Brasil, a degradação de vários biomas e ecossistemas desde os tempos coloniais favoreceu, também, a invasão biológica de animais e plan- 
tas. Entre as espécies exóticas, encontram-se muitas de origem africana. Sílvio Marcus de Souza Correa, organizou a obra Bioses africanas (2012), reunindo pesquisas a respeito da introdução de espécies africanas no Brasil.

A introdução de plantas e a disseminação de algumas espécies nem sempre foram benéficas aos ecossistemas que as receberam, como no caso da cana-de-açúcar. No entanto, algumas espécies domesticadas foram responsáveis por servirem de fonte de alimento a muitas sociedades e paralelamente propiciaram o estabelecimento de cidades, estados e até mesmo países. Mesmo havendo desejos intrínsecos, o processo de domesticação e introdução de plantas é bastante complexo, pois envolve não somente questões ligadas ao meio ambiente, mas também questões socioculturais.

Existiram fatores que levaram à escolha da domesticação e da introdução de espécies. Lucidamente, algumas espécies foram preteridas às outras. Os aspectos culturais estão ligados diretamente aos usos em geral de uma espécie do reino vegetal. As espécies vegetais têm distintas funções numa sociedade, como o fornecimento de madeira, um importante produto visado e explorado há muitos séculos. A própria composição florestal pode ser utilizada para proteção de algumas áreas.

\section{Considerações finais}

Segundo Warren Dean, a transferência de espécies e a aclimatação de espécies nativas são atividades que apresentam significados diferentes em contextos mercantilistas, liberais, científicos e comerciais, e essas atividades oferecem também uma perspectiva útil para a interpretação desses mesmos contextos. Dispõem, desta maneira, explicações para o sucesso ou insucesso de certos ramos de desenvolvimento agropecuário e industrial e demonstram a complexidade do relacionamento do ser humano com o resto do mundo biótico. A introdução e a adaptação de cada nova espécie ou variedade representa uma mudança não somente no balanço comercial do país, mas também no balanço dos elementos que compõem os ecossistemas e a própria sociedade (DEAN, 1992).

Quando a espécie é comestível, o paladar e a inserção nos hábitos alimentares são essênciais para aceitação de uma espécie. Neste grupo se enquadram as espécies frutíferas que tiveram um importante papel na alimentação do reino animal. Como explica Charles Clement: 
Assim, árvores frutíferas devem ter contribuído significativamente para a capacidade de suporte humano - a capacidade da paisagem de fornecer alimentos nutritivos suficientes e outros materiais para garantir a reprodução humana. Como produção de alimentos, estas espécies tornaram-se dominantes, inúmeras árvores frutíferas foram domesticadas e muitas espécies foram modificadas pela seleção (2006, p. 165).

Os fatores fitofisionômicos são muito importantes para a introdução de espécies frutíferas. Existe a necessidade de a planta adaptar-se às condições de solo, clima e altitude. Existem divergências explícitas na domesticação e na introdução de espécies. A intencionalidade existente na domesticação é uma diferenciação em potencial. Pode ser adotado o seguinte conceito para espécie introduzida: qualquer espécie intencional ou acidentalmente liberada pelo ser humano em um ambiente fora de sua área de distribuição natural. Dessa forma, do ponto de vista ecológico, a introdução é entendida como a inserção de uma espécie a uma dada região, de forma proposital ou não. Enquanto que a domesticação é necessariamente dotada de intencionalidade, em suma uma ação antrópica, que ocorreu na área de distribuição natural da espécie.

Na América do Sul, mais especificamente na região meridional, apenas no século XIX foram relatadas as espécies introduzidas. O botânico alemão Otto Berg, no ano de 1877, publicou uma lista com cerca de 150 espécies de plantas europeias que haviam sido introduzidas apenas na província de Buenos Aires e na Patagônia, Argentina. Em função disso, muitas espécies nativas da região foram sucumbindo às espécies exóticas. Na região dos pampas, segundo o relato de alguns botânicos, na década de 1920, somente um quarto das espécies existentes na região eram nativas (CROSBY, 1993, p. 146).

A migração e introdução de espécies nem sempre se mostrou triunfante, mas também, nem todas as espécies introduzidas são indesejadas pelos seus introdutores. No século XX, com os avanços tecnológicos, a biogeografia conseguiu trazer algumas respostas a respeito da domesticação e da dispersão de algumas espécies. A alimentação tem uma relação bastante direta com a escolha, a domesticação e a dispersão das plantas. A partir do século XIX, desenvolvimentos de vias de rodagens e aprimoramentos tecnológicos de conservação e refrigeração dos alimentos fizeram com que espécies vegetais produzidas em diferentes partes do planeta chegassem a locais onde essas espécies não eram nativas ou produzidas. É legível que nos séculos que antecederam este período, onde a troca de alimentos perecíveis era mais difícil, havia maior necessidade de migrar e domesticar as plantas. 


\section{Referências}

BALTER, Michael. Seeking Agriculture's Ancient Roots. Science, 29, june 2007, p. 1830-1835.

BEINART, William; MIDLETON, Karen. Transferências de plantas em uma perspectiva histórica: o estado da discussão. Topoi, v. 10, n. 19, jul./dez. 2009, p. 160-180. CAVALLI-SFORZA, Luigi Luca. Genes, povos e línguas. São Paulo: Companhia das Letras, 2003.

CLEMENT, C. R. 1492 and the loss of Amazonian crop genetic resources. I. The relation between domestication and human population decline. Economic Botany, 53(2), p. 188-202, 1999.

CLEMENT, Charles. Fruit trees and the transition to food production in Amazonia. BALÉE, William; ERICKSON, Clark L. (Eds.) 2006 Time and Complexity in the Neotropical Lowlands: Studies in Historical Ecology. New York: Columbia University Press.

CORREA, Sílvio Marcus de Souza (Org.). Bioses africanas no Brasil. Notas de história ambiental. Itajaí: Casa Aberta, 2012.

CROSBY, Alfred W. Imperialismo ecológico: a expansão biológica da Europa 9001900. São Paulo: Companhia das Letras, 1993.

DEAN, Warren. A ferro e fogo: A história e a devastação da Mata Atlântica Brasileira. São Paulo: Companhia das Letras, 1996.

DEAN, Warren. A Luta pela borracha no Brasil. Um estudo de história ecológica. São Paulo: Nobel, 1989.

DEAN, Warren. A botânica e a política imperial: introdução e adaptação de plantas no Brasil colonial e imperial. São Paulo: IEA/USP, 1992 (Série História das Ideologias e Mentalidades, Coleção Documentos, v. 1).

DIAMOND, Jarred. Armas, germes e aço: os destinos das sociedades humanas. Rio de Janeiro: Record, 2008

DIETRICH, Oliver. Göbekli Tepe: A Stone Age ritual center in southeastern Turkey. Actual Archaeology Magazine. Anatolia. Anual. Summer 2012.

GERHARDT, Marcos. História ambiental da erva-mate. Tese (Doutorado em História), Universidade Federal de Santa Catarina, Florianópolis, 2013. Disponível em: <http://www.bu.ufsc.br/teses/PHST0458-T.pdf>. Acesso em: 29 jul. 2013.

HAYDEN, Brian; CANUEL, Neil; SHANSE, Jennifer. What Was Brewing in the Natufian? An Archaeological Assessment of Brewing Technology in the Epipaleolithic. J Archaeol Method Theory (2013) 20:102-150. DOI 10.1007/s10816-011-9127-y. 
LACOSTE, Pablo; CASTRO, Amalia; YURI, José Antonio. Construcción de la cultura de apreciación de la fruta aporte de Las mil y una noches. Varia Historia, Belo Horizonte, v. 28, n. 48, p. 647-668, jul./dez., 2012.

LADIZINSKY, Gideon. Plant evolution under domestication. Dordrecht: Kluwer Academic, 1998. BALÉE; William. The Research Program of Historical Ecology. Annual Review of Anthropology. v. 35, p. 75-98 (Volume publication date October 2006). First published online as a Review in Advance on April 26, 2006.

MCCOOK, Stuart. La Roya del Café en Costa Rica: epidemias, innovación y medio ambiente, 1950-1995. Revista Historia, n. 59-60, enero-diciembre, p. 99, 2009. POLLAN, Michel. The Botany of Desire: a plants-eye view of the world. New York: Random House, 2001.

READER, John. Potato: a story of the propitious esculent. New Haven: Yale University Press, 2008.

SOLURI, John. Banana Cultures: Agriculture, Consumption, and Environmental Change in Honduras and the United States. Texas: University of Texas Press, 2005. ZEDER, Melinda A. Central Questions in the Domestication of Plants and Animals. Evolutionary Anthropology, n. 15, p. 105-117, 2006.

ZEDER, Melinda A. Documenting Domestication: New Genetic and Archaeological Paradigms. Berkeley: University of California Press, 2006.

WORSTER, Donald. Transformações da terra: para uma perspectiva agroecológica na História. Ambiente e Sociedade, v. 5, n. 2, 2003. 